\title{
Citizen reporting as the form of e-participation in smart cities
}

\author{
Hana Kopackova \\ Faculty of Economics and Administration \\ University of Pardubice \\ Pardubice \\ hana.kopackova@upce.cz
}

\author{
Petra Libalova \\ Faculty of Economics and Administration \\ University of Pardubice \\ Pardubice \\ petra.libalova@student.upce.cz
}

\begin{abstract}
The boom of digital technologies brought new communication channels into reporting of non-emergency incidents at the municipal level. This means that citizens have more options on how to contact their city officials but more options also mean higher complexity on both sides. Citizens need to know what channels are available and how to use them and responsible city officials need to observe more channels, which is time demanding. Since the research of non-emergency citizen reporting (NECR) systems is in its infancy, we introduce the study of 13 Czech regional capitals and their systems. In this study, we evaluate the existence of different types of NECR communication channels (phone, e-mail, electronic form, WebGis, and mobile application) and their quality based on four criteria (searchability, coverage of issues, visual geolocation, and display of sent reports).
\end{abstract}

Keywords - citizen reporting; smart cities; non-emergency; eparticipation.

\section{INTRODUCTION}

Since 2005 the concept of the smart city has been evolving from purely technical matter to the mixture of technical and social innovations. Even today, the vast amount of research concentrate on the development of technical solutions (sensor devices, network infrastructure, architectural frameworks, communication interfaces, etc.) but at the same time, there is the trend of smart government initiatives being the part of smart city projects. Smart governance covers higher efficiency and effectiveness of city government, together with the focus on citizens'needs (e.g. [24], [10], [18]). Actually, cities, in order to become smart, need to listen to their citizens; otherwise, they will spend their financial resources inefficiently on some IT gadgets. Moreover, citizens can perceive government initiatives as nontransparent if they are not listened [21].

The importance of citizen participation and engagement emphasizes many authors (e.g. [15], [23], [25], [34], [35]) and organizations. For example, OECD [5] reported "engaging citizens in active participation in policy-making is the most advanced way of strengthening government-citizen relations. It means that the government acknowledges and supports citizens' own, autonomous role in the relationship“ [5]. Michels and De Graaf [21] have studied the impact of citizen participation on local policymaking; "citizen involvement in policy-making makes people feel more responsible for public matters and increases public engagement." This statement is in line with higher citizens' needs defined by Kopackova [18].
Citizen participation can take many forms; starting with a more passive form of evaluation of the contemporary situation realized by satisfaction surveys and continuing with a vast amount of participation tools like discussion forums, e-voting, e-petitioning, decision-making tools, etc. Each tool, which is useful in a different situation, brings its pros and cons but what they have in common is the activity of citizens; their willingness to participate. This feature is also characteristic for the citizen reporting tools, which are the main topic of this paper.

Citizen reporting is a comprehensive concept covering all activities of citizens in which they actively report some incident or problem they witnessed. Such reports differ in the urgency of the incident. In the research literature, there is no precise differentiation between emergency and non-emergency incidents. It is the reason why this paper uses official recommendations for citizens as a source. For example, Northern Illinois University Department of Police and Public Safety explain, "an emergency is a serious, unexpected, and often dangerous situation requiring immediate action and that may result in personal injury or damage to property" [26]. Another example is from Racine County Wisconsin "when immediate action is required: someone's health, safety or property is in jeopardy, or a crime is in progress" [31].

Incidents that are life-threatening or such incidents with a danger of delay need a fast response; therefore, reporters should use some fast reporting system in contrast with non-emergency incidents. Reporters of emergencies should use a national emergency hotline if there is only one or national emergency phone numbers for ambulance, fire, and police. On the other hand, non-emergency incidents can be reported via diverse communication channels, which emerged with the development of digital technologies.

The rest of the paper is organized as follows. The following chapter describes the origins of the concept of non-emergency citizen reporting (NECR) system. Next chapter introduces different types of NECR channels that can be used by city governments. Chapter 4 describes the methodology of the research, whereas chapter 5 introduces the results of the evaluation of Czech regional capitals according to use of NECR systems. Chapter 6 summarizes these results and discuss future research options.

\section{NON-EMERGENCY CITIZEN REPORTING (NECR) CONCEPT}

The main idea of reporting non-emergency incidents did not come with the rise of the web and mobile applications. The 
original thought came from the 311 hotline introduced in 1996 as a first non-emergency hotline in Baltimore being the federal grant-funded demonstration project [27]. In the 1999 City of Chicago implemented the first comprehensive 311 nonemergency hotline. Till now, almost all big U.S. cities implemented some form of 311 service. The reasons for the implementation have evolved through time. First motivation was reducing the burden of 911 call centers. However, data from 311 calls have become a good source of knowledge about the state of the city, reactivity of the local government and citizens. Moreover, this system brought citizen engagement on an unexpected level.

Offenhuber [28] summarizes the view on 311 systems: “...311 systems imply a two-way contract between the government and the citizens. The city commits to responding to citizen requests in a timely manner and offers a mechanism for the citizens to track requests. In return, the citizens contribute data that again is made publicly accessible".

The concept of NECR is based on two grounded concepts that appeared in the last decade: (1) e-government 2.0, and (2) crowdsourcing. E-government 2.0 represents the transformation of government operations using a variety of technologies referred to collectively as web 2.0 (e.g. [4], [11], [2]). The umbrella term web 2.0 covers a vast pool of tools that help users to be interactive and bring new content. Web administrator is no longer solely the author of the content. Available tools comprise blogs, wikis, RSS, social networking and bookmarking, using mashups and much more (e.g. [29], [22], [6], [11], [1]). Main reasons for e-government 2.0 adoption are higher effectiveness and efficiency, together with the strengthening of transparency and accountability of governments (e.g. [9], [30], [2]). E-government itself is a broad term covering interactions with citizens (G2C), between governments and other government agencies $(\mathrm{G} 2 \mathrm{G})$, between government and employees (G2E), and between government and businesses (G2B) ([14], and [32]). The concept of NECR utilizes mainly $\mathrm{C} 2 \mathrm{G}$ interaction as citizens report nonemergency faults to the government. However, G2C interaction is also necessary. Citizens will use the NECR system only if they see that their complaints were heard and acted upon. So it is up to the government to change the status of the request or make a comment about the progress.

Crowdsourcing is a second concept explaining the essence of NECR, even if it appeared later than non-emergency reporting. Crowdsourcing represents the act of a company or institution taking a function once performed by employees and outsourcing it to an undefined (and generally vast) network of people in the form of an open call [16]. The reason for engaging crowds lies in the capability of the crowd to produce "collective intelligence" as defined by Lévy [19]. Whereas the term crowdsourcing became almost buzzword, research literature produced a plethora of different definitions. Estellés-Arolas and Ladrón-de-Guevara [13] integrated all definitions into one unifying definition, which gives us a possibility to define NECR in great detail.

"Crowdsourcing is a type of participative online activity in which an individual, organization, or company with enough means proposes to a group of individuals of varying knowledge, heterogeneity, and number, via a flexible open call, the voluntary undertaking of a task. The undertaking of the task, variable complexity and modularity, and in which the crowd should participate bringing their work, money, knowledge and/or experience, always entails mutual benefit. The user will receive the satisfaction of a given type of need, be it economic, social recognition, self-esteem, or the development of individual skills, while the crowdsourcer will obtain and utilize to their advantage that what the user has brought to the venture, whose form will depend on the type of activity undertaken."

Taking this definition as the basis, the NECR system can be defined as follows:

1. A crowd is composed of citizens.

2. The task is to collect data about non-emergency incidents.

3. Satisfaction is compensation for the crowd collecting data.

4. The role of crowdsourcer is assigned to local government for systems that are supported by them. However, in the case of apps developed by individuals and companies that do not have a clear relationship with the local government, then the developer is in the role of crowdsourcer.

5. Compensation for local government is the knowledge about the problem. Compensation for the developer is publicity together with the visibility and escalation of the problem.

6. The process is participative as citizens are participants; however, the process is not necessarily online. Nonemergency faults can be reported even by phone.

7. It uses an open call - everybody can answer the call.

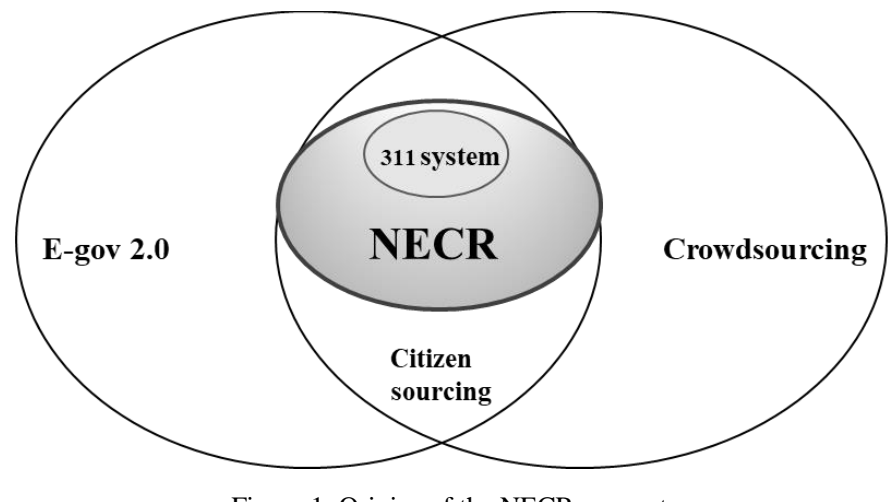

Figure 1. Origins of the NECR concept.

Figure 1 shows the relationship of described concepts. The space between those two concepts is covered by citizen sourcing, which means the coproduction of public services by citizens. Linders [20] explains the difference in roles of government and citizens "government holds primary responsibility, but citizens influence direction and outcomes, improve the government's situational awareness, and may even help execute government services on a day-to-day basis." Citizens' coproduction may take mainly these forms: ideation, voting, consultation, problem-solving, co-delivery, and reporting. However, the list is not finite, every day, new 
applications are emerging with features unexpected in the past. NECR system is based on citizen reporting, ideation, and in some cases problem-solving.

\section{TYPOLOGY OF NECR SYSTEMS}

We describe the NECR systems from the viewpoint of local governments, which means that NECR system is a tool using different channels to employ citizens as sensing devices gathering data [33]. This way of participation activates people to care more about the place they live - their city. Origination of NECR systems can be top-down, bottom-up or combined. The top-down approach means that cities take the initiative and develop or have developed some solution in contrast with bottom-up citizen initiative. The motivation of local governments in the top-down approach is the same as for 311 systems. Developers' motivation in bottom-up approach mainly concerns higher visibility whether of the problem or the developer. Desouza and Bhagwatwar [8] show possible developers' motivations as economic (prizes, business goal) or solving social problems. Widespread model of NECR system is a combination of both approaches forming a multi-channel system.

Each local government chooses a specific combination of reporting channels to form their NECR system. In this part of the paper, we will introduce new possibilities that local governments can use. However, it is clear to us that the situation in this area is changing so rapidly that this list will soon be obsolete. Therefore, we will focus on channel type rather than specific solutions. First, we start with channels invoked as the initiative of the local government.

Phone call - the original way of gathering non-emergency reports dates back to the last century. Approaches to this media differ in each municipality. Some of them use call center with unified three-digit number 311 , some have a different number, and others use more than one number for non-emergency calls divided by fault type (road maintenance, damage to municipal property, disservice of utilities, greenery damage, etc.).

E-mail - brought first online reporting possibility. The advantage of the e-mail is that it is asynchronous communication and the problem is directed to the right person. However, the e-mail is unstructured without length limitation, which means that some reports can be lengthy and incomprehensible.

Electronic form - have the same advantage of asynchronous communication; moreover, it brings a higher level of structure. The specific structure of the form depends on the needs of local government.

GIS-based web solution - geographic information systems (GIS) enrich citizen reporting on the spatial component. While using a phone, e-mail or electronic form citizens must describe the place of the incident by address or some textual description, GIS allows for selection of the place in the map [7]. The use of GIS gives municipalities' great deal of options. The least expensive solution is the use of mashup of an existing map (e.g., Google map) and electronic form. Local governments can use existing form and improve its features by adding the clickable map. The second option is the use of existing geoportal that the municipality uses and add the component for sending the reports. This solution has the advantage for users of using familiar environment. The most expensive GIS solution is specialized NECR geoportal.

Mobile application - the wave of smartphones brought new possibilities even for citizen reporting. Mobile applications for citizen reporting became popular mostly as civic apps, but the local government also initiate the creation of mobile NECR. Recently there are two main streams of mobile NECR. First is a specialized application for the non-emergency reporting in the competence of the municipality. Second can be called municipal mobile application that covers a wide range of features (e.g., traffic info, tourist info, cultural events, parking) one of which is NECR.

Social networks - gives citizens the possibility to use a familiar environment, which they use in their personal life, on the other hand, processing of this information is more demanding due to unstructured nature of information.

Local governments are not limited to channels invoked by them. Citizens often take the initiative and create so-called civic apps. Usually, such universal applications are not location specific (e.g., SeeClickFix, FixMyStreet, ImproveMyCity) and bring the possibility to report non-emergency incidents both, via the web interface and over the mobile. Universal applications can be beneficial for municipalities without their own web or mobile channel. Mostly these applications offer to send report e-mails to predefined persons as the free service. Customization and integration into municipalities CRM is a paid service.

Municipalities with their web and mobile channels do not always perceive the involvement of these universal applications as advantageous. They invested quite a lot of money into their solution and did not want it to be wasted. Moreover, some people would use their solution, and some would use universal application, which forces responsible persons to monitor more channels. That is why some officials are skeptical, feeling that "(it) simply duplicated existing channels, especially the local council website" [17].

When we change the viewpoint from local government to citizens, the benefit of universal applications is the possibility to voice dissatisfaction with the administration and bureaucracy. Fedor Gorozhanko, the developer of web application Zalivet.spb formulated the reasons: "Since 2012 I've been adding everything to the map: to visualize the problem, for mass-media and also for a kind of psychological pressure. Because when an official sees that he has a problem in his district, he knows that his superior can also see it, and so he tries to repair it as soon as possible" [12].

\section{METHODOLOGY}

The case study in this paper is based on the evaluation of selected Czech cities, which are so big that it is appropriate to exploit at least one channel for citizen reporting. Selected cities are regional capitals. In the Czech Republic, there are 13 regional capitals. The process of evaluation is depicted in figure 2. Searching for NECR systems imitated the search of an ordinary citizen who wants to report some non-emergent incident on municipal property. Examples of incidents were 
further specified as damaged benches, mess, broken pavement, uncut grass, landfills, potholes, broken lights, or abandoned vehicle. If there were no option to report the incident, then the process would stop. NECR channels were categorized into five categories (phone, e-mail, electronic form, WebGis, and mobile application), with the fact that the municipality may have one or more different channels. Found channels were evaluated according to four criteria:

a) searchability - how difficult it was to find particular channels (LOW/MEDIUM/HIGH); b) coverage of issues - eight types of issues were defined (2LOW/5-MEDIUM/8-HIGH);

c) visual geolocation - inserting an incident location by clicking on the map (YES/NO);

d) display of sent reports - if the user sees reports sent by other users (NO/LIST/MAP).

The evaluation was held in July 2018, and it is part of a longitudinal study about NECR systems in the Czech Republic.

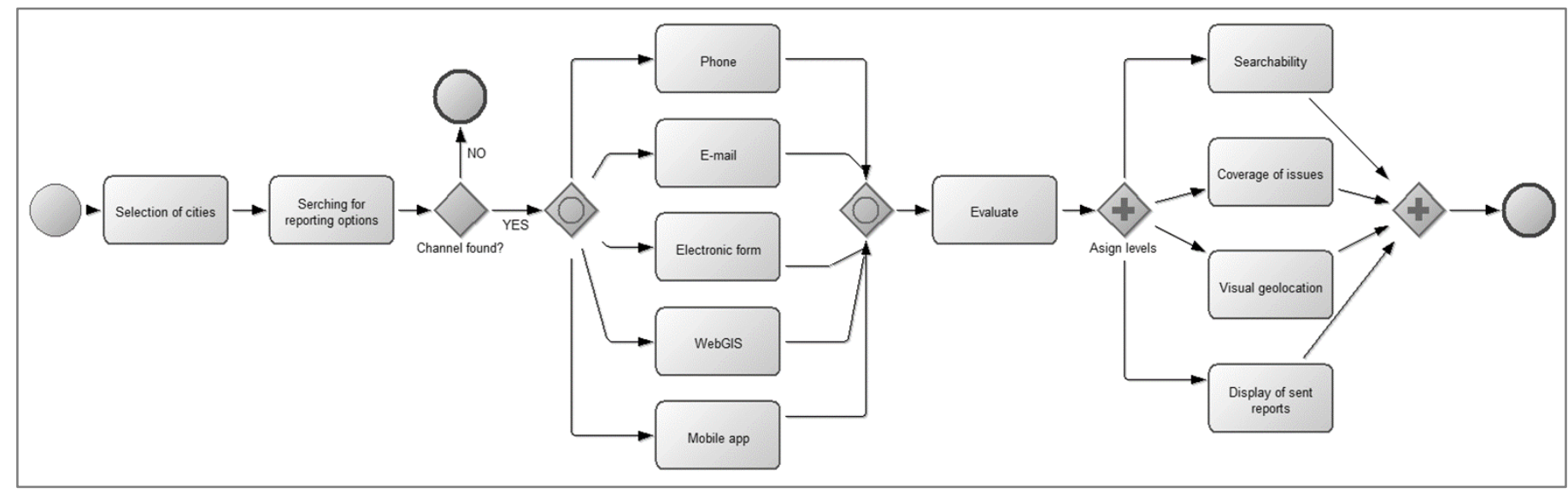

Figure 2. The process of evaluation of NECR systems in selected cities

\section{RESULTS}

Cities in the Czech Republic never used any unified phone number for non-emergencies, such as 311 hotline in the US. Each city has its number, and very frequently, there is not only one. It makes the situation difficult for citizens who want to report some non-emergency incident because they do not know what number to use.

Thirteen evaluated regional capitals differ in their size from 49000 to 1200000 . However, all of them are big enough to take advantage of specific NECR system. All cities have at least one phone number dedicated to reporting non-emergencies, so we evaluated other channels (e-mail, electronic form, WebGis, mobile application). Results of the evaluation are depicted in table 1. From this summary, it is evident that most cities offer their citizens more than one option for communication with city officials. Nevertheless, this evaluation is quantitative and does not refer to the quality of the offered solutions. That is why we set four qualitative evaluation criteria (searchability, coverage of issues, visual geolocation, and display of sent reports). The evaluation was city centered, not solution-centered, which means that if the city had more channels for NECR system, the evaluation was based on the best one. According to results, cities were classified into three categories. The first category included cities with the highest quality of NECR systems. The second category is the widest and contains cities having some minor problems. The last category contains cities with the lowest quality of NECR systems.
Table 1. Summary of NECR communication channels

\begin{tabular}{lccccc}
\hline City name & Inhab & Email & El. form & WebGIS & MA \\
Brno & 377973 & x & x & x & x \\
České Budějovice & 93470 & x & x & x & x \\
Hradec Králové & 92929 & & X & & x \\
Jihlava & 50559 & & & x & \\
Karlovy Vary & 49046 & $\mathrm{x}$ & $\mathrm{x}$ & & $\mathrm{x}$ \\
Liberec & 103853 & & $\mathrm{x}$ & $\mathrm{x}$ & \\
Olomouc & 100378 & & $\mathrm{x}$ & & \\
Ostrava & 291634 & $\mathrm{x}$ & $\mathrm{x}$ & & \\
Pardubice & 90044 & & $\mathrm{x}$ & & $\mathrm{x}$ \\
Plzeň & 170548 & & & $\mathrm{x}$ & $\mathrm{x}$ \\
Praha & 1280508 & $\mathrm{x}$ & $\mathrm{x}$ & $\mathrm{x}$ & $\mathrm{x}$ \\
Ústínad Labem & 92984 & $\mathrm{x}$ & & & \\
Zlín & 75117 & $\mathrm{x}$ & $\mathrm{x}$ & & $\mathrm{x}$ \\
\hline
\end{tabular}

A. Cities with the highest score-České Budějovice, Plzeň, Liberec

All three cities in this category offer their citizens channels that are easy to find, cover all spectra of issues, use visual geolocation, and show sent reports in the form of a map. Figures 3,4 , and 5 show sent reports for selected cities. Although the results of the evaluation are the same for these cities, their technical solutions profoundly differ.

The city of Plzeň use their own solution, which is both; WebGIS based (Plznito) and mobile (Plzeň občan). Mobile application put together information from local government and the reporting module for citizens as the municipal application. Both ways, mobile app, and WebGIS can be used to see the 
status of reported incidents or to report a new one. Both channels have a similar user interface, which makes the use of it much more comfortable.

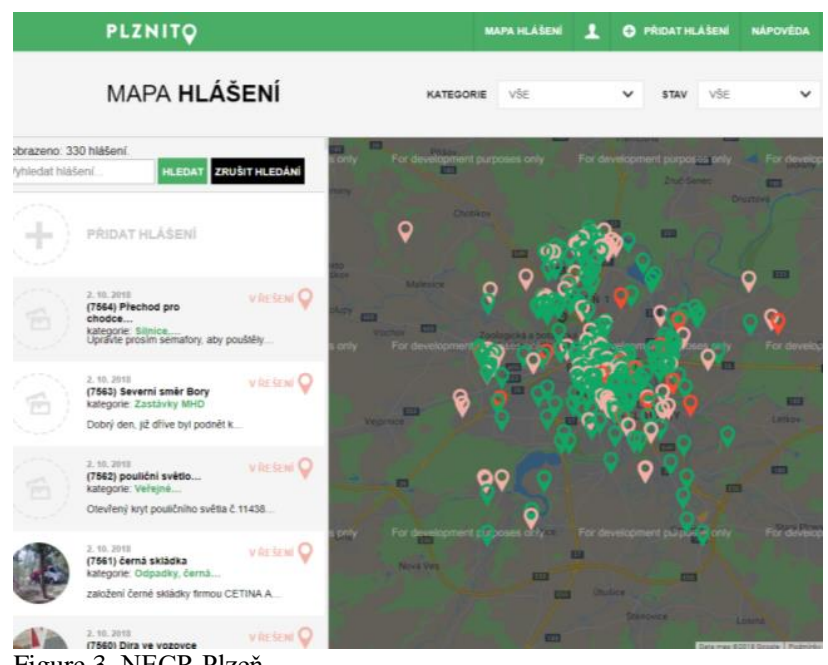

Figure 3. NECR Plzeň

České Budějovice uses DejTip application, which is mobile application operated by the third party, related to a broader area than the city, and specialized on reporting. This city also uses their own electronic form and WebGIS solution, which is based on DejTip application. The number of communication channels for citizens is the highest; however, the usability would be higher if the displayed reports would also show the description of the issue, not only the category and the address.

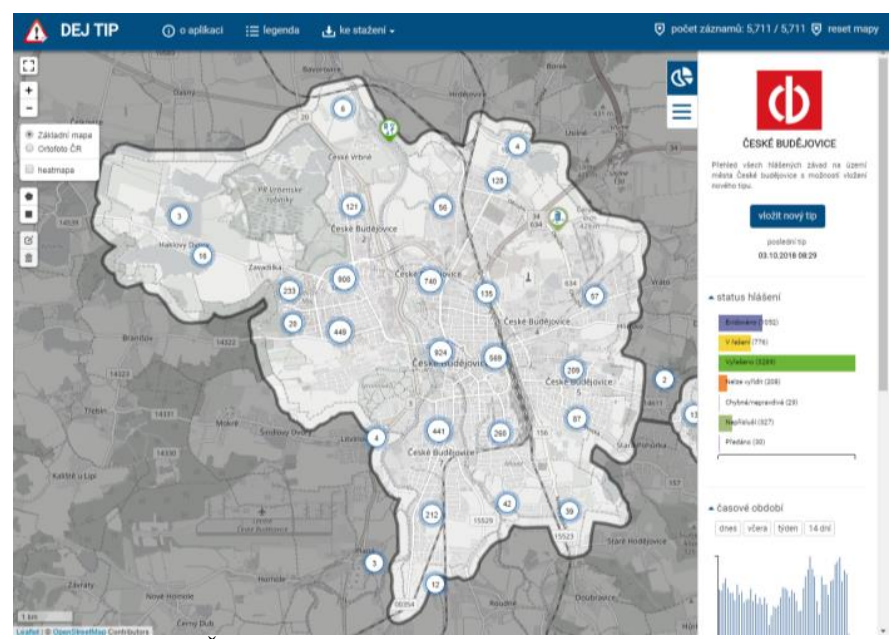

Figure 4. NECR České Budějovice

The city of Liberec uses geoportal Marushka, which they use as a GIS solution for the evidence of municipal property. Description of the issue is displayed after clicking on the object in the map. However, it is not possible to filter issues according to date or issue type, as it is possible in Plzeň and České Budějovice.

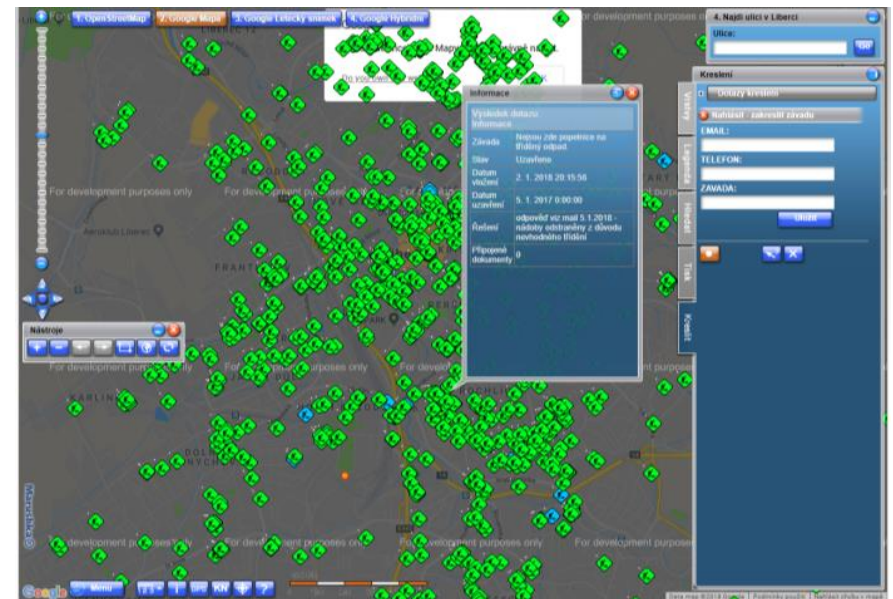

Figure 5. NECR Liberec

\section{B. Cities with minor quality issues - Ostrava, Pardubice, Prague, Jihlava, Brno}

Five cities did not comply with one quality criterion. City of Ostrava and Pardubice display sent reports only in the form of the list. Prague and Jihlava do not display sent reports at all. Brno has lower coverage of issues (roads, street lights, and suburban forests).

\section{Cities with more than one quality issue - Karlovy Vary, Hradec Králové, Olomouc, Ústí nad Labem}

Four cities have more quality issues than one. At first, no city in this category uses visual geolocation. Another challenging issue was the display of sent reports. Karlovy Vary presents them in the form of the list; other cities do not display them at all (Hradec Králové, Olomouc, Ústí nad Labem). The city of Hradec Králové also have low coverage of issues (streetlights). The worst score obtained the city of Ústí nad Labem, which offer their citizens only e-mail for reporting nonemergency issues and it was challenging to find.

\section{CONCLUSIONS}

This paper evaluated the use of NECR systems in 13 Czech regional capitals. The results showed that cities offer their citizens various channels to report non-emergencies. Although the electronic form is the most popular, mobile applications and WebGIS solutions are also popular among evaluated cities. Quality of offered solutions differ, but we can find three cities as examples of good practice; Plzeň, České Budějovice, and Liberec. These cities can be seen as real smart cities listening to the voice of their citizens.

As the limitation of the study, we can mention the focus of the study only on the supply side at the local government level. Future research should consider the level of use by citizens, their satisfaction and the responsiveness of local government. However, this research will be possible only if cities publish sent reports with their status. 


\section{ACKNOWLEDGMENT}

The paper has been completed with the kind support of SGS_2019_17 project of Faculty of Economics and Administration, University of Pardubice.

\section{REFERENCES}

[1] R. Abbott, "Delivering quality-evaluated healthcare information in the era of Web 2.0: design implications for Intute: Health and Life Sciences," Health Informatics Journal, vol. 16, no. 1, 2010, pp. 5-14.

[2] E. Bonsón, L. Torres, S. Royo, and F. Flores, “Local e-government 2.0: Social media and corporate transparency in municipalities," Government information quarterly, vol. 29, no. 2, 2012, pp. 123-132.

[3] D.C. Brabham, "Crowdsourcing as a model for problem solving: An introduction and cases," Convergence, vol. 14, no. 1, 2008, pp. 75-90.

[4] S. Chun, S. Shulman, R. Sandoval, and E. Hovy, "Government 2.0: Making connections between citizens, data and government," Information Polity, vol. 15, no. (1, 2), 2010, pp. 1-9.

[5] Citizens as Partners. OECD handbook on information, consultation and public participation in policy-making, 2001, [Online]. Available: https://www.internationalbudget.org/wp-content/uploads/Citizens-asPartners-OECD-Handbook.pdf

[6] E. Constantinides and S.J. Fountain, "Web 2.0: Conceptual foundations and marketing issues," Journal of direct, data and digital marketing practice, vol. 9, no. 3, 2008, pp. 231-244.

[7] M. DeMeritt and E. Writer, "Simplifying citizen reporting," ArcUserMagazine for ESRI Software User, vol. 14, no. 1, 2011, pp. 26-27.

[8] K.C. Desouza and A. Bhagwatwar, "Citizen apps to solve complex urban problems," Journal of Urban Technology, vol. 19, no. 3, 2012, pp. 107136.

[9] M. Dimitriu, "Bringing citizens closer to public administration Innovative ideas leading to an increased public participation within the decision making process," In EGPA Annual Conference, 2008.

[10] S. Dirks and M. Keeling, "A vision of smarter cities: How cities can lead the way into a prosperous and sustainable future," Somers, NY: IBM Institute for business Value, 2009.

[11] B.E. Dixon, "Towards e-government 2.0: An assessment of where egovernment 2.0 is and where it is headed," 2010. [Online]. Available: https://scholarworks.iupui.edu/bitstream/handle/1805/4334/Dixon-2010towards.pdf? sequence $=1$

[12] K. Ermoshina, "Democracy as pothole repair: Civic applications and cyber-empowerment in Russia," Cyberpsychology: Journal of Psychosocial Research on Cyberspace, vol. 8, no. 3, 2014.

[13] E. Estellés-Arolas and F. González-Ladrón-De-Guevara, "Towards an integrated crowdsourcing definition," Journal of Information science, vol. 38, no. 2, 2012, pp. 189-200.

[14] GAO (General Accounting Office), David McClure. (2001). "Electronic Government: Challenges Must Be Addressed with Effective Leadership and Management." July, 11. http://feapmo.gov/links.asp Accessed on September 22, 2003.

[15] A. Ho and P. Coates, "Citizen-initiated performance assessment: The initial Iowa experience," Public Performance \& Management Review, vol. 27, 2004, pp. 29-50.

[16] J. Howe, “The rise of crowdsourcing," Wired magazine, vol. 14, no. 6, 2006, pp. 1-4.

[17] S.F. King and P. Brown, "Fix my street or else: using the internet to voice local public service concerns," in Proceedings of the 1st international conference on Theory and practice of electronic governance, ACM,2007, pp. 72-80.

[18] H. Kopackova, "Reflexion of citizens' needs in city strategies: The case study of selected cities of Visegrad group countries," Cities, vol. 84, 2019, pp. 159-171.

[19] P. Levy, “Collective Intelligence: Mankind's Emerging World in Cyberspace," Cambridge, Massachusetts: Perseus Books, 1997.

[20] D. Linders, "From e-government to we-government: Defining a typology for citizen coproduction in the age of social media," Government Information Quarterly, vol. 29, no. 4, 2012, pp. 446-454.

[21] A. Michels and L. De Graaf, "Examining citizen participation: Local participatory policy making and democracy," Local Government Studies, vol. 36, no. 4, 2010, pp. 477-491.

[22] S. Murugesan, "Understanding Web 2.0," IT Professional Magazine, vol. 9, no. 4, 2007, pp. 34-42.

[23] T. Nabatchi, A. Sancino, and M. Sicilia, "Varieties of participation in public services: The who, when, and what of coproduction," Public Administration Review, vol. 77, 2017, pp. 766-776.

[24] T. Nam and T.A. Pardo, "Smart city as urban innovation: Focusing onmanagement, policy, and context," in Proceedings of the 5th International Conference on Theory and Practice of Electronic Governance, September 26-28, Tallinn, Estonia, 2011.

[25] M.I. Neshkova and H.D. Guo, "Public participation and organizational performance: Evidence from state agencies," Journal of Public Administration Research and Theory, vol. 22, 2012, pp. 267-288.

[26] Northern Illinois University Department of Police and Public Safety. [Online]. Available: https://niu.edu/publicsafety/emergency/vs-nonemergency.shtml

[27] J.C. O'Byrne, “The Diffusion and Evolution of 311 Citizen Service Centers in American Cities from 1996 to 2012-A Study to Identify the Catalysts for the Adoption of Citizen Engagement Technology" (Doctoral dissertation, Virginia Tech), 2015, unpublished.

[28] D. Offenhuber, "Infrastructure legibility - a comparative analysis of open311-based citizen feedback systems," Cambridge Journal of Regions - Economy and Society, vol. 8, no. 1, 2014, pp. 93-112.

[29] T. O'Reilly,. "What Is Web 2.0? Design Patterns and Business Models for the Next Generation of Software," September 30, [Online]. Available: http://www.oreillynet.com/pub/a/oreilly/tim/ news/2005/09/30/what-isweb-20.html

[30] L. Pratchett, "New technologies and the modernization of local government: An analysis of biases and constraints," Public Administration, vol. 77, no. 4, 1999, pp. 731-750.

[31] Racine County Wisconsin. [Online]. Available: https://racinecounty.com/government/communications/911education/911-vs-non-emergency

[32] K. Siau and Y. Long, "Synthesizing e-government stage models-a metasynthesis based on meta-ethnography approach," Industrial Management \& Data Systems, vol. 105, no. 4, 2005, pp. 443-458.

[33] T.D. Susanto, M.M. Diani, and I. Hafidz, "User Acceptance of eGovernment Citizen Report System (a Case Study of City113 App)," Procedia Computer Science, vol. 124, 2017, pp. 560-568.

[34] D. Swindell and J.M. Kelly, "Linking citizen satisfaction to performance measures: A preliminary evaluation," Public Performance and Management Review, vol. 24, 2000, pp. 30-52.

[35] W.N. Wu and K. Jung, "A missing link between citizen participation, satisfaction, and public performance: Evidences from the city and county of San Francisco," International Journal of Public Sector Performance Management, vol. 2, 2016, pp. 392-410. 